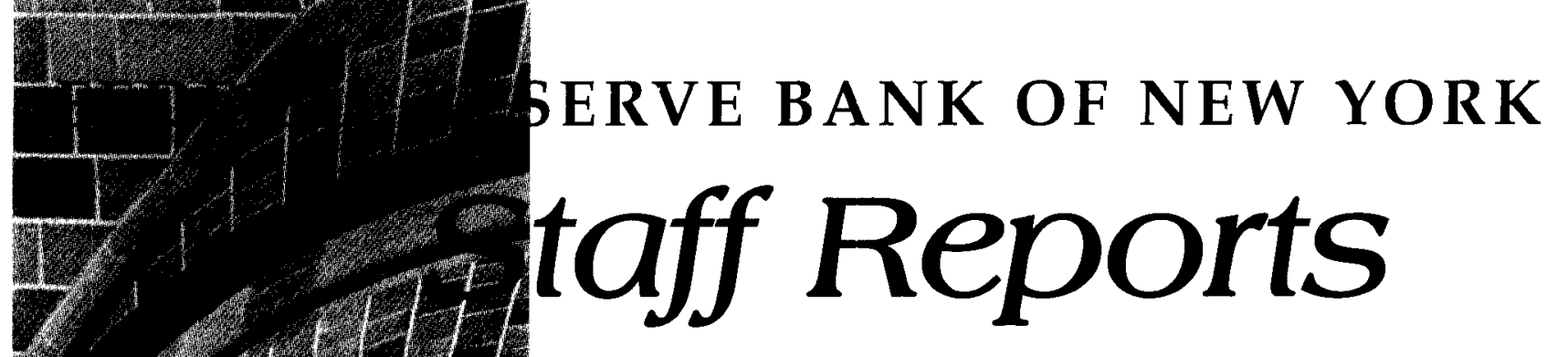

Error Correction Mechanisms and

SHORT-RUN EXPECTATIONS

Angelos A. Antzoulatos

Number 10

February 1996 


\title{
Error Correction Mechanisms and Short-run Expectations
}

\author{
Angelos A. Antzoulatos \\ International Macroeconomics Function \\ Research and Market Analysis Group \\ Federal Reserve Bank of New York
}

\begin{abstract}
Reflecting the nature of economic decisions, the error-correction mechanism (ECM) in the error-correction representation of a system of co-integrated variables may arise from forward-looking behavior. In such a case, the estimated ECM coefficients may misleadingly appear to be insignificant or to have the opposite-than-expected sign if the variables in the error-correction representation do not adequately capture short-run expectations. This paper explores the nature of this problem with a theoretical model for consumption and demonstrates how severe the problem can be with U.S. data. Because the conditions for similar erroneous inferences are likely to apply to many other settings, the paper also recommends a reexamination of the evidence in cases where the ECM appears to be insignificant or to display the "wrong" sign.
\end{abstract}


The author thanks seminar participants at the Federal Reserve Bank of New York, and especially Juann Hung, Carol Osler, and Michael Boldin of FRBNY, and Edward Feasel of George Washington University for many insightful comments and suggestions. Of course, these individuals are not responsible for any remaining errors. 


\section{Introduction}

Since the publication of Engle and Granger's (1987) seminal paper, "Cointegration and Error Correction: Representation, Estimation, and Testing," it has been widely known that a system of co-integrated variables has an error-correction representation in which the vector autoregression (VAR) in differenced variables contains an error correction mechanism (ECM). In Engle and Granger's paper, the ECM emerges as a statistical property of the data, which supports theoretical explanations that stress an ECM's resemblance to a feedback control rule driven by some partial adjustment mechanism (see, for example, Davidson et al. 1978 and Hendry et al. 1990). Nevertheless, because the nature of economic decisions suggests that the ECM may arise from forward-looking behavior, it may also reflect expectations about future events (see, among others, Campbell 1987 and Alogoskoufis and Smith 1991). Thus, as this paper shows, estimated ECM coefficients can misleadingly appear to be insignificant or to have the opposite-than-expected sign if the other explanatory variables in the errorcorrection representation generate poor conditional forecasts for the system's endogenous variables. In turn, the erroneous inferences about the ECM coefficients can lead to misspecified econometric models in which the ECM's promise of better short-run forecasts will not materialize.

This paper explores the problem of erroneous inferences regarding the estimated ECM coefficients by using the system of consumption and income. It then demonstrates the potential magnitude of these errors with 
U.S. data. Specifically, the second section combines the forward-looking nature of consumption with a partial adjustment mechanism to derive a theoretical model for consumption. In this model, consumption growth is increasing in contemporaneous and (expected) future income growth and decreasing in the ECM, while the ECM is increasing in future income growth. Conversely, in the typical error correction representation, consumption growth is a function of the ECM and of lagged values of consumption and income growth. Provided that these lagged values generate good income-growth forecasts, the estimated ECM coefficient in the errorcorrection representation will be negative. If not, as in the case of U.S. data, the coefficient will be positively "biased." This bias reflects the positive correlation of future income growth with both the ECM and consumption growth. The bias can be so severe that the ECM coefficient can misleadingly appear to be insignificant or, even worse, positive. How can this problem be addressed? The bias can be reduced by including in the errorcorrection representation other stationary variables that can help predict income growth.

The empirical evidence, in Section 3, illustrates the problem of erroneous inferences regarding estimated ECM coefficients. The ECM (the lagged residuals of the co-integrating regression of log consumption on $\log$ income and a constant) is positively correlated with future income growth. However, its coefficient in the error correction representation is positive and insignificant. We test whether this result is due to the poor incomegrowth forecasts generated by lagged consumption and income growth terms by including contemporaneous income growth in the regression (the working hypothesis is that expected values differ from realized ones by an 
unpredictable stochastic term (Cumby et al. 1983). In this equation, the ECM coefficient becomes negative but remains insignificant. However, the addition of future income growth makes the coefficient significantly negative at the 5 percent level. The addition of another variable that can help predict future income growth (the first lag of the growth rate of the Composite Index of Eleven Leading Indicators) increases the coefficient's significance to the 1 percent level. Overall, in accordance with the theory outlined in Section 2, each additional variable correlated with future income growth helps increase both the significance level and the absolute value of the estimated ECM coefficient.

The forward-looking nature of economic decisions and the difficulty of modeling expectations suggest that the conditions for erroneous inferences about the estimated ECM coefficients are likely to apply to many other settings. For this reason, Section 4 recommends a reevaluation of the evidence in cases where the ECM coefficient appears to be insignificant or with the wrong sign.

\section{The Case of Consumption and Income}

\section{A. A Theoretical Model for the Error Correction Mechanism}

Equations 1 through 3 summarize the problem faced by a forward-looking individual who maximizes the expected value of a time-separable utility function subject to a borrowing constraint:

subject to

$$
\operatorname{Max} E_{t}\left\{\sum_{k=0}^{T}\left(\frac{1}{1+\delta}\right)^{k} u\left(C_{t+k}\right)\right\} \quad(\delta>0)
$$

$$
C_{t} \leq X_{t}
$$




$$
X_{t}=R S_{t-1}+I_{t}=R\left(X_{t-1}-C_{t-1}\right)+I_{t} \quad(R \geq 1)
$$

The timing and the nature of his decisions are as follows: at the beginning of period $t$, he decides how much to consume, $C_{t}$, in order to maximize his expected utility (equation 1 ) over the remaining planning horizon. As a result of the borrowing constraint (equation 2) consumption cannot exceed the individual's total assets, $X_{t} . X_{t}$ is equal to the savings carried over from $t-1, R S_{t-1}=R\left(X_{t-1}-C_{t-1}\right)$, plus the realized income, $I_{t}$, as described by equation 3 . For simplicity, and without loss of generality, the real interest rate ( $R$ is equal to one plus the real interest rate) and the length of the planning horizon, $T$, are taken as exogenous. Because the analysis is based on the stochastic implications of the permanent income hypothesis (PIH), no particular assumptions are needed for the income process (Hall 1978). Capital letters denote levels, small letters denote logs and $\Delta$ is the difference operator. Thus, $\Delta c_{t}=c_{t}-c_{t-1}$ denotes consumption growth at $t$.

There is no closed-form solution for optimal consumption under uncertainty and borrowing constraints. However, by using the first-order condition of the individual's optimization problem, it is clear that optimal consumption is increasing in contemporaneous assets and expected future income (for a formal analysis, see, among others, Schechtman and Escudero 1977, Deaton 1991 and Antzoulatos 1994a). In mathematical terms, $C_{t-}$ ${ }_{I}$ in equation 4 is increasing in $X_{t-1}$ and $E_{t-1} I_{t+k}(k \geq 0)$ :

$$
C_{t-1}=C_{t-1}\left(X_{t-1} ; E_{t-1} I_{t} ; E_{t-1} I_{t+1} ; E_{t-1} I_{t+2} ; \ldots\right)
$$

Similarly, $E_{t-I} C_{t}$ is increasing in $E_{t-I} I_{t+k}(k \geq 0)$. 
When the individual is at an interior solution at $t-1$ (nonbinding constraint), expected consumption change, $E_{t-1} \Delta C_{t}$, will be unrelated to $E C M_{t-l}$ and any other economic variable observed at $t-1$ or earlier, as the permanent income hypothesis postulates (Hall 1978). This reflects the fact that both $C_{t-1}$ and $E_{t-1} C_{t}$ are increasing in expected income. The error-correction term, however,

$$
E C M_{t-1}=C_{t-1}-I_{t-1}
$$

will be increasing in $E_{t-1} I_{t+k}(k \geq 0)$ (equation 4).

However, when the individual faces a binding constraint at $t-1$ (corner solution), expected consumption change will be increasing in $E_{t-1} I_{t+k}(k \geq 0)$ and decreasing in $E C M_{t-1}$. At a corner solution, it is $C_{t-1}=X_{t-1}=R S_{t-1}+I_{t-1}$. Thus,

$$
E C M_{t-1}=\left(R S_{t-2}+I_{t-1}\right)-I_{t-1}=R S_{t-2}
$$

Also, $S_{t-1}=0, X_{t}=I_{t}$ and

$$
\begin{aligned}
E_{t-1} \Delta C_{t} & =E_{t-1} C_{t}-C_{t-1}=E_{t-1} C_{t}\left(E_{t-1} X_{t} ; E_{t-1} I_{t+1} ; E_{t-1} I_{t+2} ; \ldots\right)-C_{t-1} \\
& =E_{t-1} C_{t}\left(E_{t-1} I_{t} ; E_{t-1} I_{t+1} ; E_{t-1} I_{t+2} ; \ldots\right)-\left(R S_{t-1}+I_{t-1}\right)
\end{aligned}
$$

Because $E_{t-1} C_{t}$ is increasing in $E_{t-1} I_{t+k}(k \geq 0)$, expected consumption change will increase in $E_{t-1} I_{t+k}(k \geq 0)$ as well. (For a more formal discussion in the Euler equation framework, see Antzoulatos 1994b.) One caveat arises: if the individual is expected to be at a corner solution at $t, E_{t-1} C_{t}=E_{t-1} X_{t}=E_{t-1} I_{t}$ consumption change will increase in contemporaneous income only. Further, 
$E_{t-1} \Delta C_{t}$ will be decreasing in $R S_{t-2}$ and consequently in $E C M_{t-1}$.

In terms of the ECM, when the individual is at a corner solution, $E C M_{t-l}$ will tend to be positively correlated with $E_{t-1} I_{t+k}(k \geq 0)$. The reason is that the individual will spend all his savings plus contemporaneous income at $t-1$-rising $C_{t-1}$ and $E C M_{t-1}$-when he expects higher income in the future. However, when he gets to a corner solution (that is, when $C_{t-1}$ becomes equal to $\left.X_{t-1}\right) C_{t-1}$-and $E C M_{t-1}$-cannot increase further in anticipation of high future income. Consequently, at the limit, $E C M_{t-1}$ may be uncorrelated with $E_{t-1} I_{t+k}(k \geq 0)$.

The above analysis postulates the following function for expected aggregate consumption change, the sum of individual $E_{t-1} \Delta C_{r}$ :

$$
E_{t-1} \Delta C_{t}=f\left(E C M_{t-1}, E_{t-1} I_{t} E_{t-1} I_{t+1}, E_{t-1} I_{t+2}, \ldots\right)
$$

Because of the individuals who are at a corner solution at $t-1, E_{t-1} \Delta C_{t}$ will tend to be decreasing in $E C M_{t-1}$ and increasing in $E_{t-1} I_{t+k}(k \geq 0)$. Thus, in the $\log$-linear version of equation 7 , given by equation 8 below, ${ }^{1} \beta_{0}$ is expected to be negative, while $\gamma_{k}(k \geq 0)$ are expected to be positive (the ECM's log version is given by equation 9). Also, under the assumption that realized consumption change differs from that expected by an unpredict-

1 A first-order Taylor expansion of equation 7 around the point $\left(0, I_{t-1}, E_{t-1} I_{p}, E_{t-1} I_{t+1}, \ldots\right)$ gives $E_{t-1} \Delta C_{t}=f\left(0, I_{t-1}, E_{t-1} I_{p} E_{t-1} I_{t+1}, \ldots\right)+f_{1}^{*} E C M_{t-1}+f_{2} *\left(E_{t-1} I_{t}-I_{t-1}\right)+$ $f_{3} *\left(E_{t-1} I_{t+1}-E_{t-1} I_{t}\right)+f_{4} *\left(E_{t-1} I_{t+2}-E_{t-1} I_{t+1}\right)+\ldots+u_{t}$ $f_{i}$ denotes the partial derivative of $f($.) with respect to the $i$ argument.

With the exception of $f_{l}$, all $f_{i}$ are expected to be positive. Next, since consumption and income appear to be $I(I)$ and co-integrated in logs, the log version of this equation is used, as in Campbell and Mankiw (1990 and 1991). 
able stochastic term, $u_{t}$ should be unrelated to any variables observed at $t-I$ or before.

(8) $\Delta c t=$ constant $+\beta_{0} E C M_{t-1}+\gamma_{0} E_{t-1} \Delta i_{t}+\gamma_{1} E_{t-1} \Delta i_{t+1}+\gamma_{2} E_{t-1} \Delta i_{t+2}+\ldots+u_{t}$.

$$
E C M_{t-1}=c_{t-1}-i_{t-1}
$$

Further, because of the individuals who are at an interior solution at $t-1$, $E C M_{t-1}$ will tend to be increasing in $E_{t-1} I_{t+k}(k \geq 0)$ even when the $E C M_{t-1}$ is uncorrelated with future income for individuals at a corner solution. As a result, the omission of $E C M_{t-1}$ in equation 8 will induce a negative bias in the regression estimates of $\gamma_{k}(k \geq 0)$. This bias reflects the positive relationship between future income and $E C M_{t-I}$ in conjunction with $\beta_{O}$ 's negative sign, as in the typical case of omitted variables in a regression equation analyzed in Johnston $\left(1984\right.$, p. 260). Similarly, the omission of $E_{t-1} I_{t+k}$ $(k \geq 0)$ will induce a positive bias in $\beta_{O}$ 's estimate which, as a result, can be insignificant or even positive. ${ }^{2}$

In this theoretical model, the partial adjustment of consumption to

2 In the limiting case, when the ECM is uncorrelated with future income for the individuals who are at a corner solution, the bias in aggregate data would arise from the aggregation across all individuals. It would also arise in pooled micro data when the individual income processes are correlated; that is, when they contain a common "aggregate" component in addition to idiosyncratic ones. Of course, if constrained and unconstrained individuals could be identified in micro data, estimating equation 8 for the latter would produce no bias as all coefficients would be zero. But there would be some bias for the constrained individuals only when the ECM is correlated with future income. 
expected income, driven by the binding borrowing constraint, induces the negative relationship between $\Delta c_{t}$ and $E C M_{t-1}$ and the positive relationship between $\Delta c_{t}$ and $E_{t-1} I_{t+k}(k \geq 0)$. Also, the forward-looking nature of consumption induces the positive relationship between $E C M_{t-1}$ and $E_{t-1} I_{t+k}$ $(k \geq 0)$. Nevertheless, the same conclusions, culminating in the same bias for the estimated ECM coefficients, can be derived from more general models that combine forward-looking behavior with some partial adjustment mechanism. Section IIB presents such a model (adapted from Davidson and MacKinnon 1993, p. 680) whose very general structure clearly demonstrates that the problems of erroneous inferences about ECM coefficients may be pervasive.

\section{B. An Alternative Model}

Let optimal consumption $c_{t}^{*}$ be a function of contemporaneous and expected future income (equation 10). The coefficients $\mu_{k}(k \geq 0)$ are positive, while $\varepsilon_{t}$ is a stochastic disturbance. Because of some sort of adjustment costs, people cannot set actual consumption, $c_{t}$, equal to $c_{t}^{*}$. Instead, $c_{t}$ adjusts towards $c_{t}{ }^{*}$ as described by equation 11 . (Equation 11 can also be justified by partial adjustment to income shocks resulting from small utility costs of deviation from the optimal consumption path, as in Caballero 1995.) The term ( $1-\xi)$ measures the speed of adjustment, while $e_{t}$ is a stochastic term.

$$
c_{t}^{*}=\mu+\mu_{0} i_{t}+\mu_{1} E_{t} i_{t+1}+\mu_{2} E_{t} i_{t+2}+\ldots+\mu_{p} E_{t} i_{t+p}+\varepsilon_{t} .
$$




$$
c_{t}-c_{t-1}=(1-\xi)\left(c_{t}^{*}-c_{t-1}\right)+e_{t} \quad(0<1-\xi<1) .
$$

Subtracting $c_{t-1}$ from both sides of equation 10 , rearranging terms and multiplying both sides of the resulting equation with $(1-\xi)$ result in the following expression for equation 11 :

$$
\Delta c_{t}=c_{t}-c_{t-1}=(1-\xi) \mu-(1-\xi)\left(c_{t-1}-\lambda i_{t-1}\right)+\psi_{0}\left(i_{t}-i_{t-1}\right)
$$

$+\psi_{1}\left(E_{t} i_{t+1}-i_{t}\right)+\psi_{2}\left(E_{t} i_{t+2}-E_{t} i_{t+1}\right)+\ldots+\psi_{p}\left(E_{t} i_{t+p}-E_{t} i_{t}+p-1\right)+\left[(1-\xi) \varepsilon_{t}+e_{t}\right]$

$$
=(1-\xi) \mu-(1-\xi)\left(c_{t-1}-\lambda i_{t-1}\right)+\sum_{k=0}^{p} \psi_{k} E_{t} \Delta i_{t+k}+u_{t}
$$

where $\psi_{p}=(1-\xi) \mu_{p}, \psi_{k}=(1-\xi) \sum_{j=0}^{p-k} \mu_{p-j}(k=0,1,2, \ldots, p-1)$ and

$\lambda(1-\xi)=\psi_{0}$. As in equation 8 , all the coefficients of the income-growth terms, $\psi_{k}(0 \leq k \leq p)$, are positive, while the coefficient of the ECM, -(1$\xi)$, is negative. Also, because both equations contain a constant, the income-growth terms can be be expressed as deviations from their means and, thus, reflect short-run income expectations.

The derivation of equation 12 illustrates the analytical foundations of the error-correction representation. Although equation 12 departs from the strict stochastic implications of the permanent income hypothesis, it is consistent with the forward-looking nature of consumption and the empirical regularities found in the U.S. consumption data. That is, contrary to the $\mathrm{PIH}$ postulate that consumption growth should-at a first approximationbe unpredictable, consumption growth is correlated with contemporaneous and future income growth (Antzoulatos 1994b). Also, log consumption and 
income are integrated of order one and appear to be co-integrated (this means that the term $\left(c_{t-1}-\lambda i_{t-1}\right)$ is stationary).

\section{Short-Run Income Expectations and the Error Correction Representation}

If $c_{t}$ and $i_{t}$ are $I(I)$ and co-integrated, as they appear to be, the typical singleequation error-representation for consumption growth would be:

$$
\begin{gathered}
\Delta c_{t}=\alpha+\phi_{1} \Delta i_{t-1}+\ldots+\phi_{p} \Delta i_{t-p+1}+\theta_{1} \Delta c_{t-1}+\ldots \\
+\theta_{p} \Delta c_{t-p+1}+\beta E C M_{t-1}+u_{t}
\end{gathered}
$$

The coefficient $\beta$, which corresponds to $\beta_{0}$ in equation 8 and to $-(1-$ $\xi$ ) in equation 12 , should be negative. (If not, under the assumption that the $E C M_{t-1}$ is positively correlated with future income, which is confirmed by the data, the system of consumption and income would be unstable.) Also, the comparison of equations 8 and 12 with 13 indicates that the terms $\Delta i_{t-m}$ and $\Delta c_{t-m}(m=1 \ldots p)$ can be thought of as proxies of $E_{t-1} \Delta i_{t+k}(k \geq 0)$. If these proxies do not generate good forecasts for $\Delta \mathrm{i}_{t+k}(k \geq 0), \beta$ will be a positively biased estimate of $\beta_{0}$, a reflection of the $E C M_{t-1}$ 's positive correlation with $E_{t-1} \Delta i_{t+k}(k \geq 0)$ in conjunction with the latter's positive correlation with $\Delta c_{t}$. This is similar to the typical case of omitted variables in a regression equation (Johnston 1984, p. 260).

Consequently, when $\Delta i_{t-m}$ and $\Delta c_{t-m}(m=1 \ldots p)$ do not generate good forecasts for $E_{t-1} \Delta i_{t+k}(k \geq 0), \beta$ may appear to be insignificant or even positive. However, the inclusion of other stationary variables that are correlated with expected income growth will help reduce $\beta$ 's "bias." Such variables, labeled here as exogenous, allow a richer specification of the 
system's short-run dynamics and more efficient estimation without undermining the analytical foundations of the error-correction representation.

\section{An Example}

A more concrete example helps illustrate the nature of the bias, the importance of good income proxies, and the efficiency gains afforded by exogenous variables which can help improve income growth forecasts. For simplicity, but without loss of generality, let $\Delta c_{t}$ in equation 8 be a function of $E C M_{t-1}, E_{t-1} \Delta i_{t}$ and $E_{t-1} \Delta i_{t+1}$ only. Let also $\Delta c, E C M, E \Delta i_{t}$ and $E \Delta i_{t+1}$ denote the vectors of realizations of these variables; $X$ the matrix with columns $E C M, E \Delta i_{t}$ and $E \Delta i_{t+1}$; and $\gamma$ the coefficient vector $\gamma^{\prime}=\left(\beta_{0}, \gamma_{0}, \gamma_{l}\right)$.

The theoretical model for consumption growth-the equivalent of 8 is given by:

$$
\Delta c=X \gamma+u
$$

Next, let $z_{0, t-1}$ and $z_{1, t-1}$ be two proxies of expected future income, as in equation 13. These proxies can be lagged values of income or consumption growth or exogenous stationary variables. Let also the matrix $Z$ of the regressors in equation 13 have as columns $E C M, z_{0}$ and $z_{1}$. The OLS coefficients $\zeta^{\prime}=\left(\beta, \zeta_{0}, \zeta_{1}\right)$ are:

$$
\zeta=\left(Z^{\prime} Z\right)^{-1} Z^{\prime} \Delta c .
$$

Substituting equation 14 into equation 15 gives (under the assumption $Z^{\prime} u=0$ ): 


$$
\begin{aligned}
\zeta=\left(Z^{\prime} Z\right)^{-1} Z^{\prime} \Delta c=\left(Z^{\prime} Z\right)^{-1} Z^{\prime}(X \gamma+u) & =\left(Z^{\prime} Z\right)^{-1} Z^{\prime} X \gamma \\
+\left(Z^{\prime} Z\right)^{-1} Z^{\prime} u=\left(Z^{\prime} Z\right)^{-1} Z^{\prime} X \gamma & =\Theta \gamma
\end{aligned}
$$

The $(3,3)$ matrix $\Theta=\left(Z^{\prime} Z\right)^{-1} Z^{\prime} X$ has as columns the regression coefficients of $E C M, E \Delta i_{t}$ and $E \Delta i_{t+1}$ (matrix X) on $E C M, z_{0}$ and $z_{1}$. Let $\Theta$ be

$$
\Theta=\begin{array}{lll}
1 & \pi & \omega \\
0 & \pi_{0} \omega_{0} \\
0 & \pi_{1} \omega_{1}
\end{array},
$$

which implies the following regression equations:

$$
\begin{aligned}
& E C M_{t-1}=1 E C M_{t-1}+0 z_{0, t-1}+0 z_{1, t-1} ; \\
& E_{t} \Delta i_{t}=\pi E C M_{t-1}+\pi_{0} z_{0, t-1}+\pi_{1} z_{1, t-1} ; \text { and } \\
& E_{t} \Delta i_{t+1}=\omega E C M_{t-1}+\omega_{0} z_{0, t-1}+\omega_{1} z_{1, t-1}
\end{aligned}
$$

So, the coefficient $\beta$ in equation 16 , the equivalent of the ECM coefficient in the error-correction representation (equation 13), will be:

$$
\beta=\beta_{0}+\pi \gamma_{0}+\omega \gamma_{1}
$$

Because $E C M_{t-1}$ and $\Delta i_{t+k}(k=0,1)$ are positively correlated, one can reasonably assume that the coefficients $\pi$ and $\omega$ in equations 18 and 19 are 
positive. ${ }^{3}$ Taking into account that $\gamma_{0}$ and $\gamma_{1}$ are expected to be positive, $\beta$ 's bias and the possibility that $\beta$ is insignificant or positive are increasing in the value of $\pi$ and $\omega$. Thus, the bias will be highest when $z_{i, t-1}(i=0,1)$ are unrelated to $E_{t-1} \Delta i_{t+k}(k=0,1)$ in which case $\pi_{i}$ and $\omega_{i}(i=0,1)$ are equal to zero while $\pi$ and $\omega$ attain their highest values. In general, as the explanatory value of $z_{i, t-1}(i=0,1)$ for $E_{t-1} \Delta i_{t+k}(k=0,1)$ increases, the value of $\pi$ and $\omega$ (and the bias) will decrease. The bias will be totally eliminated only when $z_{0}=E_{t-1} \Delta i_{t}$ and $z_{1}=E_{t-1} \Delta i_{t+1}$; in this case, $\pi_{0}=\omega_{1}=1$ and $\pi=\omega=\pi_{l}=\omega_{0}=0$.

3 By analogy to Johnston's (1984, pp. 81-86) analysis, the value of $\pi$ and $\omega$ is increasing in the correlation coefficient between $E C M_{t-1}$ and $E_{t-1} \Delta i_{t+k}(k=0,1)$, and decreasing in the correlation coefficients between $E C M_{t-1}$ and $z_{i, t-1} \quad(i=0,1)$ and between $E_{t-1} \Delta i_{t+k}(k=0,1)$ and $z_{i, t-1}(i=0,1)$.

As a reminder, Johnston analyzes the case with three interrelated variables $Y, X_{2}$ and $X_{3}$ in the model:

$$
Y=\beta_{1}+\beta_{2} X_{2}+\beta_{3} X_{3} .
$$

Let $r_{12}, r_{13}$ and $r_{23}$ denote their simple correlation coefficients and $s_{i}(i=1,2,3)$ denote their standard errors, with the subscript 1 referring to the $Y$ variable.

Johnston shows that the estimates of $\beta_{2}$ and $\beta_{3}$, denoted as $b_{2}$ and $b_{3}$, satisfy the relationships:

$$
b_{2}=\frac{r_{12}-r_{13} r_{23}}{1-r_{23}^{2}} \frac{s_{1}}{s_{2}} ; \quad b_{3}=\frac{r_{13}-r_{12} r_{23} s_{1}}{1-r_{23}^{2}} \frac{1}{s_{3}} .
$$

Focusing on the first relationship, the value of $b_{2}$ is increasing in the correlation coefficient between $Y$ and $X_{1}\left(r_{12}\right)$, and decreasing in the correlation coefficient between $Y$ and $X_{3}$ and between $X_{2}$ and $X_{3}\left(r_{13}\right.$ and $\left.r_{23}\right)$.

Johnston's analysis further implies that the value of $\pi$ and $\omega$ will decrease as the explanatory value of $z_{0}$ and $z_{1}$ for $E_{t \cdot 1} \Delta i_{t+k}(k=0,1)$ increases. 


\section{Results}

All series are constructed from CITIBASE data. Real per-capita consumption, nondurables and services, and personal disposable income are measured in 1982 dollars. The sample is restricted to 1953:1 through 1988:4 to hedge against the distortive impact on the income series of the Korean War period and the revisions of the original consumption and income series (Campbell and Mankiw 1990). Nevertheless, the results are qualitatively the same for the whole sample period, 1947 through 1990. Also, the threemonth Treasury Bill rate, secondary market, and the growth rate of the Composite Index of Eleven Leading Indicators and the University of Michigan's Consumer Confidence Index are used as instruments. These instruments help predict the growth rate of personal disposable income despite the fact that income growth exhibits very little autocorrelation. The critical values for the ADF tests are taken from Charemza and Deadman (1992, Tables 2 and 3). Throughout this section, the numbers in parentheses below the estimated coefficients correspond to t-statistics, while one, two, and three asterisks denote significance at the 10,5 , and 1 percent levels, respectively.

Table 1 summarizes the correlation coefficients between income growth and some variables of interest. The first row indicates that $\Delta i_{t}$ exhibits very little autocorrelation: with the exception of the third lead, all the autocorrelation coefficients are well below 0.10 . The second row confirms the expectation that consumption growth should be positively correlated with contemporaneous and future income growth. Taken together, the first two rows indicate that lagged values of $\Delta i_{t}$ and $\Delta c_{t}$ will generate poor forecasts of future income growth, $\Delta i_{t+k}(k \geq 1)$. The third row confirms the expectation that $E C M_{t}$ should be positively correlated with $\Delta i_{t+k}(k>1)$. 
Finally, the last row shows that the growth rate of the Composite Index of Eleven Leading Indicators, denoted as $D L 3_{t}$, is positively correlated with $\Delta i_{t+k}(k>1)$. As such, $D L 3_{t}$ is expected to help reduce the bias of the $E C M_{t}$ coefficient in the error-correction representation for consumption growth.

Further, the correlation coefficients between $E C M_{t}$ and $\Delta i_{t-k}, \Delta c_{t-k}$, $D L 3_{t-k}(k=0,1,2,3, \ldots)$ are below 0.2 and frequently below 0.1 . These low coefficients imply that $\pi$ and $\omega$ in equations 18 and 19 will likely be positive; consequently, $\beta$ will be a positively biased estimate of $\beta_{0}$ (see the discussion in the previous footnote).

\section{Table 1:}

Correlation Coefficients

\begin{tabular}{lccccc} 
& $\Delta i_{t}$ & $\Delta i_{t+1}$ & $\Delta i_{t+2}$ & $\Delta i_{t+3}$ & $\Delta i_{t+4}$ \\
\hline$\Delta i_{t}$ & 1.000 & 0.055 & 0.012 & 0.158 & -0.040 \\
$\Delta c_{t}$ & 0.529 & 0.299 & 0.092 & 0.238 & 0.197 \\
$E C M_{t}$ & & 0.314 & 0.217 & 0.188 & 0.197 \\
$D L 3_{t}$ & & 0.288 & 0.134 & 0.245 & 0.157 \\
\hline
\end{tabular}

Notes:

a) Source: CITIBASE.

b) Sample period: 1953:1 through 1988:4.

c) $\Delta i, \Delta c$ : growth rates, per capita personal disposable income and consumption (nondurables and services), $1982 \$$.

d) $E C M_{t}$ : residuals of co-integrating regression of $\mathrm{c}_{t}$ on $\mathrm{i}_{\mathrm{t}}$ and a constant.

e) $D L 3_{t}$ : growth rate, third month of $t^{\text {th }}$ quarter, Composite Index of Eleven Leading Indicators. 
A series of ADF tests established that $c_{t}$ and $i_{t}$ are $I(I)$. The lower critical values at the 1 percent level for 100 and 150 observations are -2.70 and -2.68 (Table $2, \mathrm{~m}=0$ ) without intercept, and -2.90 and -2.79 (Table $3, \mathrm{~m}=0$ ) with intercept. The number of available observations is approximately 140 . Regressing consumption growth, $\Delta c_{t}$, on $c_{t-1}$ and $\Delta c_{t-k}(k=1,2)$ gave a t-statistic for $c_{t-1}$ of 5.13 which, obviously, is not significantly negative. The inclusion of an intercept in the regression gave a t-statistic of -0.07 which is not significantly negative either. Next, regressing the second difference, $\Delta \Delta c_{t}$, on $\Delta c_{t-1}$ and $\Delta \Delta c_{t-k}(k=1,2)$ resulted in a t-statistic for $\Delta c_{t}$ of -3.07 without and -5.20 with an intercept. Both are below the lower critical values at the 1 percent level. Similarly, in the regression of $\Delta i_{t}$ on $i_{t-1}$ and $\Delta i_{t-k}$, $k=1,2$, the t-statistics of $i_{t-1}$ were 4.79 without and -0.29 with intercept. In the $\Delta \Delta i_{t}$ regression, the appropriate t-statistics were -3.99 and -5.64 , respectively, which are below the lower critical values at the 1 percent level. The stationarity tests were also conducted with three and four lags of $\Delta c_{t}$ and $\Delta i_{t}$. Because the conclusions regarding the order of integration for $c_{t}$ and $i_{t}$ are the same, only the results for $k=1,2$ are reported to save space.

The results of the co-integrating regression, the equivalent of equation 9 above, at the first step of Engle and Granger's (1987) two-step estimator, are summarized below:

$$
c_{t}=\underset{(-4.48)(209.6)}{-0.041+0.912 i_{t}+v_{t} ; \quad} \quad \mathrm{R}^{2}=0.997, D . W .=0.378
$$

In general, the OLS estimate of $i_{t}$ 's coefficient is biased. However, as 
Davidson and McKinnon (1993, p. 724) remark, the bias seems to be least severe when the $R^{2}$ is close to 1 , as is the case here.

Regressing the change in the residuals, $\Delta \mathrm{v}_{t}$, on $\mathrm{v}_{t-1}$ and $\Delta \mathrm{v}_{t-1}$ established that the null of non-co-integration between $c_{t}$ and $i_{t}$ can be rejected at the 5 percent level. In more detail, the $t$-statistic of $v_{t-1}$ was -3.30 , while the lower critical value for 100 and 150 observations at the 5 percent level with one estimated parameter (Table $2, \mathrm{~m}=1$ ) is -2.87 .

To establish that the joint distribution of $c_{t}$ and $i_{t}$ is an error-correction system, in the second step of Engle and Granger's estimator, consumption growth is regressed on $v_{t-1}$ and five lags of $\Delta c_{t}$ and $\Delta i_{t}$. An $\mathrm{F}$ test indicated that, with the exception of $\Delta c_{t-1}$, all the lagged terms were jointly insignificant. More specifically, the $\mathrm{F}$ test for the joint hypothesis $\Delta c_{t-k}=\Delta i_{t-m}=0$ $(k=2,3,4,5$ and $m=1,2,3,4,5)$ was $\mathrm{F}(9,139)=1.29$, far below the critical values at all conventional significance levels. Proceeding with a "general to specific" modeling approach, the more parsimonious equation is estimated below:

$$
\begin{aligned}
\Delta c_{t}= & 0.005+0.023 v_{t-1}+0.236 \Delta c_{t-1} ; \quad \mathrm{R}^{2}=0.06, D . W .=2.02 . \\
& (6.24)^{* * *} \quad(0.63) \quad(2.84)^{* * *}
\end{aligned}
$$

In this equation, the estimated ECM coefficient, $\beta=0.023$, is not only insignificant, but its sign is opposite of that expected. Moreover, there is strong evidence of high-order serial correlation in the residuals. The positive coefficient of $\Delta c_{t-1}$ probably reflects $\Delta c_{t-1}$ 's positive correlation with $\Delta i_{t+k}$ $(k \geq 0)$.

To test whether the positive sign and the statistical insignificance of $\beta$ are due to the fact that lagged values of $\Delta c_{t}$ and $\Delta i_{t}$ are poor proxies for 
future income growth, $\Delta i_{t}$ is included in the set of the regressors. (In the spirit of equation 20 , this manipulation will render $\pi=0$ and reduce $\beta$ 's positive bias.) The working hypothesis is that, under rational expectations, expected income growth differs from that realized by an unpredictable stochastic term (Cumby et al. 1983). Because this term is likely to be correlated with the error in the error-correction representation, the new equation should be estimated with instrumental variables (IV). In addition, since the time aggregation of consumption may induce an $M A(1)$ term in the error, the instruments should be lagged at least two periods (see Campbell and Mankiw 1990 and 1991 for details). The instruments are a constant, $c_{t-2}, i_{t-}$ 2, $r_{t-k}(k=2,4), \Delta c_{T, t-k}(k=2,4)$ and $\Delta i_{t-k}(k=2,5) . r_{t}$ denotes the quarterly average of the three-month Treasury Bill rate (secondary market), while $\Delta c_{T, t}$ denotes the growth rate of total consumption. Also, $c_{t-1}$ and $i_{t-1}$ are used instead of the residuals of the co-integrating regression.

As the equation below indicates, the coefficients of $c_{t-1}$ and $i_{t-1}$ have the expected sign, that is, they imply a negative $\beta$, but are insignificant, while the coefficient of $\Delta i_{t}$ is positive and significant at the 1 percent level. On the positive side, this model-as well as the next one-passes diagnostic tests for serial correlation and autoregressive conditional heteroskedasticity $(\mathrm{ARCH})$ in the residuals. For parsimony, the equation does not include $\Delta c_{t-l}$, which is insignificant.

$$
\begin{aligned}
& \Delta c_{t}=-0.001-0.059 c_{t-1}+0.054 i_{t-1}+0.480 \Delta i_{t} ; \quad R^{2}=0.196 \text { D.W. }=2.16 \\
& (-0.17)(-1.27) \quad(-1.27) \quad(4.59) * * *
\end{aligned}
$$

More important, the inclusion of future income growth (which is 
equivalent to setting $\omega=0$ in 20) makes the coefficients of $c_{t-1}$ and $i_{t-1}$ significant at the 5 percent level. In addition, all coefficients have the theoretically predicted sign: ${ }^{4}$

$$
\begin{aligned}
\Delta c_{t}=-0.003 & -0.093 c_{t-1}+0.085 i_{t-1}+0.430 \Delta i_{t}+0.231 \Delta i_{t+1} ; \quad R^{2}=0.319, D . W .=1.88 \\
(-0.80) & (-2.04)^{* *}(2.04)^{* *} \quad(4.34)^{* * *}(2.27)^{* *}
\end{aligned}
$$

The results were similar for the whole sample, 1947 through 1990. The ECM coefficient was marginally significant at the 10 percent level (t-statistic -1.68) in the unrestricted equation, which included lagged values of $\Delta c_{t}$ and $\Delta i_{t}$. The inclusion of $D L 3_{t-1}$ in the set of the regressors raised ECM's significance to the 5 percent level (t-statistic -2.1). The addition of $\Delta c_{t}$ further raised the significance level to 1 percent (t-statistic -3.25). Also, in

4 To conform with the majority of the literature, the last two equations are also estimated with OLS. As with IV estimation, $\beta$ turns negative in the first equation but is still insignificant. In the second, $\beta$ becomes significant at the 5 percent level.

$$
\begin{aligned}
& \Delta c_{t}=0.003 \quad-0.039 v_{t-1}+0.308 \Delta i_{t} \quad R^{2}=0.287, D . W .=1.90 ; \\
& (7.38)^{* * *}(-1.18) \quad(7.41)^{* * *} \\
& \Delta c_{t}=0.002 \quad-0.069 v_{t-1}+0.311 \Delta i_{t}+0.169 \Delta i_{t+1} \quad R^{2}=0.375, D . W .=1.92 \text {. } \\
& (5.07)^{* * *}(-2.18)^{* *}(7.96)^{* * *}(4.44)^{* * *}
\end{aligned}
$$

Further, the inclusion of $D L 3_{t-1}$ increases both the t-statistic of $\beta$ and its absolute value. This provides further evidence about the hypothesis that "exogenous" variables that can help predict income growth may help reduce the bias of the ECM coefficient:

$$
\begin{aligned}
\Delta c_{t}= & -0.002-0.077 v_{t-1}+0.283 \Delta i_{t}+0.157 \Delta i_{t+1}+0.043 D L 3_{t-1} ; \quad R^{2}=0.410, \text { D.W. }=2.03 . \\
& (4.82)^{* * *}(-2.48)^{* * *}(7.21)^{* * *}(4.21)^{* * *}(2.86)^{* * *}
\end{aligned}
$$


accordance with the theory, the ECM coefficient kept increasing in absolute value as more regressors correlated with future income were added.

Finally, an error-correction model was estimated for income. The original model included six lags of consumption and income growth, as well as the error-correction mechanism and the first lag of the growth rate of the Composite Index of Eleven Leading Indicators. A series of F tests indicated that only the first three lags of consumption growth and the error-correction mechanism had significant predictive power for income growth. As one might expect from the theoretical analysis and the correlation coefficients in Table 1, the coefficient of $E C M_{t-I}$ was positive and significant at the 1 percent level. The $E C M_{t-1}$ 's coefficient positive sign provides further support for the argument that a positive $\beta$ in equation 13 would indicate an unstable system.

\section{Conclusion}

This paper uses a consumption example to argue that biased error-correction coefficients may be pervasive in error-correction models that are meant to capture behavior that is influenced in an essential way by expectations. The paper uses a simple theoretical model to show that the ECM coefficient in the error-correction representation of aggregate consumption will be biased upwards if some consumers are borrowing-constrained and some are not. If some consumers are borrowing-constrained, expected consumption growth is negatively correlated with the ECM and positively correlated with contemporaneous expectations of future income growth. Similarly, the ECM is positively correlated with contemporaneous expectations of future income if some consumers are not borrowing-constrained. Hence, the esti- 
mated ECM coefficient will be biased upwards if the other right-hand-side variables in the error-correction representation for consumption are poor proxies of future income expectations. The crucial aspects of the model are the forward-looking nature of consumption and the partial adjustment induced by binding borrowing constraints. Naturally, the model's conclusions can be justified by other theoretical paradigms that combine forwardlooking behavior with some partial adjustment mechanism.

The paper also demonstrates that the theoretical predictions are borne out by U.S. data on consumption (nondurables and services) and disposable income. Lagged growth rates of these two series are poor proxies of future income growth and, presumably, of consumers' income expectations. In the typical error-correction representation, which includes only these (poor) proxies in the right-hand side, the ECM coefficient is positive but insignificant. However, when better predictors of future income growth are added to the right-hand-side, the estimated ECM coefficient eventually turns negative and significant, as predicted by the theory.

More generally, the paper demonstrates the risks inherent in treating the ECM as a mere statistical property of the data, without regard to the economic forces behind it. It also holds the promise of helping to alleviate the problems of inefficient estimation, misspecified econometric models, and poor short-run forecasts that arise from erroneous inferences about the estimated ECM coefficients. Given the forward-looking nature of economic decisions and the difficulty of modeling expectations, such problems are expected to be pervasive. Therefore, a reexamination of the evidence seems warranted in cases where the ECM appears to be insignificant or to have the opposite-than-expected sign. 


\section{References}

Alogoskoufis, George, and Ron Smith. 1991. "On Error Correction Models: Specification, Interpretation, Estimation." Journal of Economic Surveys 5, no 1: 97-128.

Antzoulatos, Angelos A. 1994a. "Credit Rationing and Rational Behavior." Journal of Money, Credit, and Banking 26, no 2: 182-202.

Antzoulatos, Angelos A. 1994b. "Borrowing Constraints, Income Expectations and the Euler Equation: Theory and Evidence." Economics Letters 45: 323-27.

Caballero, Ricardo J. 1995. "Near-Rationality, Heterogeneity and Aggregate Consumption." Journal of Money, Credit, and Banking 27, no 1:29-48.

Campbell, John Y. 1987. "Does Saving Anticipate Declining Labor Income? An Alternative Test of the Permanent Income Hypothesis." Econometrica 55, no 6: 1249-73.

Campbell, John Y., and N. Gregory Mankiw. 1990. "Permanent Income, Current Income, and Consumption." Journal of Business and Economic Statistics 8, no 3: 265-79.

Campbell, John Y., and N. Gregory Mankiw. 1991. "The Response of Consumption to Income: A Cross-Country Investigation." European Economic Review 35, no 4: 723-56.

Charemza, Wolciech W., and Derek F. Deadman. 1992. New Directions in Econometric Practice. United Kingdom: Edward Elgar Publishing Limited.

Clarida, Richard H. 1994. "Cointegration, Aggregate Consumption, and the Demand for Imports: A Structural Econometric Investigation." American Economic Review 84, no 1: 298-08.

Cumby, Robert E., John Huizinga, and Maurice Obstfeld. 1983. "Two-Step Two-Stage Least Squares Estimation in Models with Rational Expectations." Journal of Econometrics 21: 333-55.

Davidson, E.H., and David F. Hendry. 1981. "Interpreting Econometric Evidence: The Behavior of Consumers' Expenditure in the U.K." European Economic Review 16: 177-94.

Davidson, Russell, and James G. MacKinnon. 1993. Estimation and Inference in Econometrics. New York: Oxford University Press. 
Davidson, J.E.H., D.F. Hendry, F. Srba, and S. Yeo. 1978. "Econometric Modelling of the Aggregate Time-Series Relationship between Consumers' Expenditure and Income in the United Kingdom." Economic Journal 88: 661-92.

Deaton, Angus. 1991. "Saving and Liquidity Constraints." Econometrica 59, no 5: 1221-48.

Engle, Robert F., and C.W.J. Granger. 1987. "Co-Integration and Error Correction: Representation, Estimation, and Testing." Econometrica 55, no 2: 251-76.

Engle, Robert F., and Byung Sam Yoo. 1987. "Forecasting and Testing in Co-Integrated Systems." Journal of Econometrics 35: 143-59.

Gali, Jordi. 1990. "Finite Horizons, Life-Cycle Savings, and Time-Series Evidence on Consumption." Journal of Monetary Economics 26: 433-52.

Granger, C.W.J. 1981. "Some Properties of Time Series Data and their Use in Econometric Model Specification." Journal of Econometrics 16: 121-30.

Hall, Robert E. 1978. "Stochastic Implications of the Life Cycle-Permanent Income Hypothesis: Theory and Evidence." Journal of Political Economy 86, no 6: 501-17.

Hamilton, James. 1994. Time Series Analysis. Princeton, N.J.: Princeton University Press.

Hendry, D.F., J.H. Muellbauer, and A. Murphy. 1990. "The Econometrics of DHSY." In J.D. Hey and O. Winch, eds., A Century of Economics: 100 Years of the Royal Economic Society and the Economic Joumal. Oxford: Basil Blackwell.

J. Johnston. 1984. Econometric Methods. 3rd Edition. McGraw-Hill, Inc.

Nelson, Charles R. 1987. "A Reappraisal of Recent Tests of the Permanent Income Hypothesis." Journal of Political Economy 95, no 3: 641-46.

Philips, Peter C.B., and Mico Loretan. 1991. "Estimating Long-Run Equilibria." Review of Economic Studies 58: 407-43.

Schechtman, Jack, and Vear L.S. Escudero. 1977. "Some Results on 'An Income Fluctuation Problem."' Journal of Economic Theory 16: 151-66. 


\section{Staff Reports}

CENTRAL BANK INDEPENDENCE AND DisinflationaRy CREDIBILITY: A MisSing LiNK?

by Adam Posen. May 1995.

THE COSTS AND BENEFITS OF DUAL TRADING

by Hun Y. Park, Asani Sarkar, and Lifan Wu. June 1995.

SHORT-TERM SPECULATORS AND THE ORIGINS OF NEAR-RANDOM-WALK

EXCHANGE RATE BEHAVIOR

by C.L. Osler. July 1995.

HEAD AND SHOULDERS: NOT JUST A FLAKY PATTERN

by C.L. Osler and P.H. Kevin Chang. August 1995.

Using Option Prices to Estimate Realignment Probabilities IN THE EUROPEAN MONETARY SYSTEM

by Allan M. Malz. September 1995.

AN EFFICIENT, THREE-STEP ALGORITHM FOR ESTIMATING ERROR-CORRECTION MODELS WITH AN APPLICATION TO THE U.S. MACROECONOMY

by Michael D. Boldin. October 1996.

THE RELATIONSHIP BETWEEN GOVERNMENT FINANCIAL CONDITION AND EXPECTED TAX RATES REFLECTED IN MUNICIPAL BOND YIELDS

by Sangkyun Park. November 1995.

PReserving Firm Value through Exit: The Case of Voluntary LiQuidations by Michael J. Fleming and John J. Moon. December 1995.

THE EFFeCtS of INFlation on Wage Adjustments in Firm-Level Data:

GREASE OR SAND?

by Erica L. Groshen and Mark E. Schweitzer. January 1996. 